\title{
PROJETO LOGOS - EDUCAÇÃO SEXUAL EM ESCOLAS DE ENSINO MÉDIO
}

Universidade Estadual do Beal

felipebeal_@hotmail.com

Bruno Humberto Fontana

Universidade Estadual do Oeste do Paraná - UNIOESTE brunohfontana@hotmail.com

Dayanne Patricia Vicentin

Universidade Estadual do Oeste do Paraná - UNIOESTE dayavicentin@gmail.com

Hemanuelle Samia de Aguiar Barreto Dutra Universidade Estadual do Oeste do Paraná - UNIOESTE manu_samia@hotmail.com

Marly Daólio Alves

Universidade Estadual do Oeste do Paraná - UNIOESTE marlyalves@brturbo.com

Tiago Lucietto Krielow

Universidade Estadual do Oeste do Paraná - UNIOESTE tiagolucietto@live.com

Wagner Emmanuel de Morais Farias Universidade Estadual do Oeste do Paraná - UNIOESTE wagner_emmanuel@hotmail.com

\section{Resumo}

Esse artigo é uma análise das atividades de extensão universitária desenvolvidas por alunos do Curso de Medicina da Universidade Estadual do Oeste do Paraná (UNIOESTE) durante o ano de 2011. O projeto se intitula Logos - conhecer para prevenir e tem como objetivo principal informar e dirimir possíveis dúvidas de jovens do Ensino Médio da região do Oeste do Estado do Paraná sobre prevenção de doenças sexualmente transmissíveis (DST), gravidez precoce não planejada, além de abordar temas como preconceito e sexualidade. Tais assuntos são abordados com realizações de dinâmicas. A realização da atividade justifica-se devido ao alto contingente de adolescentes grávidas involuntária e precocemente e também a grande quantidade de jovens que se tornam ativos sexualmente no Brasil e que necessitam de 


\title{
Uirs $)$ EXTENSIO
}

informação, pois o início precoce da vida sexual pode ser um agravante para o comportamento de risco frente a DST. Durante esse ano (2011) foi atingido um público de 707 pessoas. Em cada uma das apresentações realizou-se uma avaliação (através de questionários) antes e após a palestra, sendo coletados 83 pares de questionários. De modo geral, os resultados dessa avaliação foram positivos, demonstrando aquisição de conhecimento e crença na mudança de atitudes frente à sexualidade, evidenciando a relevância do projeto para a divulgação do conhecimento.

Palavras-chave: Doenças Sexualmente Transmissíveis. Educação Sexual. Gravidez na adolescência. HIV. Sexualidade.

\section{LOGOS PROJECT - SEX EDUCATION IN HIGH SCHOOL}

\begin{abstract}
This article is an analysis of university extension activities developed by students of Medicine, from the Universidade Estadual do Oeste do Paraná (UNIOESTE), during the year 2011. The project is titled LOGOS - Knowing to Prevent - and its main objective is to inform and settle possible doubts of young high school students in the region of Western Paraná on prevention of sexually transmitted diseases (STD), unplanned early pregnancy, as well as addressing themes such as prejudice and sexuality. Such matters are dealt with dynamical activities. The realization of the activity is justified due to the high contingent of involuntary and early pregnancies and also to large amount of young people who become sexually active in Brazil and need information, because the early onset of sexual activity may be an aggravating factor for risk behavior for STD. During this year (2011) was reached an audience of 707 people. In each lecture was held an evaluation (using questionnaires) before and after the lectures, and were collected 83 pairs of questionnaires. Overall, the results of this assessment were positive, demonstrating acquisition of knowledge and belief in changing attitudes towards sexuality, indicating the relevance of the project for the dissemination of knowledge.
\end{abstract}

Keywords: Sexually Transmitted Diseases. Sex Education. Pregnancy in adolescence. HIV. Sexuality 


\section{INTRODUÇÃO}

A adolescência é uma fase do desenvolvimento humano caracterizada por profundas mudanças individuais e sociais que marca a transição entre a infância e a idade adulta. A faixa etária considerada pela Organização Mundial da Saúde (OMS, 1965) como correspondente a essa etapa vai dos 10 aos 19 anos. No entanto, mais que um período cronologicamente rígido, a adolescência é uma fase individualizada que traduz uma modificação dinâmica no processo de maturação biopsicossocial do ser humano (LOPES, 1993).

Considerando-se a idade proposta pela OMS para a adolescência - 10 a 19 anos -, pode-se afirmar que a população nessa faixa etária soma uma grande parcela da população brasileira, pois, de acordo com o Instituto Brasileiro de Geografia e Estatística (IBGE), em 2010, a população brasileira de jovens na faixa etária de 10 a 19 anos era correspondente a $17,9 \%$ da população brasileira.

$\mathrm{Na}$ adolescência, o jovem assume mudanças de valores e de estilo de vida, afastandose dos padrões estabelecidos por seus pais e criando sua própria identidade utilizando, para tanto, informações do seu cotidiano. Como expõe Béria e Barros (1998), ao adolescente já é permitido tomar decisões em vários aspectos de sua vida, inclusive na esfera sexual.

Contudo, apesar de todo o desenvolvimento sociocultural e tecnológico ocorrido no século XX, informações relacionadas aos aspectos de crescimento e desenvolvimento biopsicossocial e sexual não têm alcançado de forma ampla e adequada a maior parte dos adolescentes, ocasionando entre esses altos índices de desinformação sobre diferentes aspectos. De maneira geral, o adolescente não recebe na família, muito menos na escola, informações que envolvam a sexualidade e, quando tem acesso, essas são muitas vezes limitadas e inadequadas, provenientes, principalmente, de amigos e de pessoas pouco preparadas para tal função.

Pode-se perceber esse despreparo ou mesmo preconceito, tanto por parte dos pais quanto dos professores, em tratar assuntos envolvidos com sexualidade no texto de vários autores (CANO, 2000; CARDOSO, 2004; COSTA, 1986; LOPES, 1993; OSÓRIO, 1989; REICH, 1988).

Essa falta de discussão da sexualidade, seja por falta de profissionais capacitados ou seja por preconceito, aliado aos valores distorcidos passados de pai para filho ou mesmo entre amigos e ao pensamento mágico do adolescente, deixam os jovens muito vulneráveis a 
infecção por Doenças Sexualmente Transmissíveis - DST, a gravidezes indesejadas e, também, ao preconceito.

O pensamento mágico anteriormente citado pode ser entendido como uma crença na própria invulnerabilidade, representada pela afirmação "Isto nunca vai acontecer comigo", como afirma Pinheiro (2000). Bortoldi e Pessoa (1997) também o traz como um fator que induz os jovens a não usar métodos contraceptivos mesmo tendo informações a respeito deles, o pensamento mágico do adolescente o faz acreditar que está imune e, suas aventuras amorosas estão protegidas contra uma gravidez inesperada.

Para se comprovar isso, basta analisar dados sobre gravidez na adolescência. Em Cascavel-PR, segundo Márcia Fontanella (coordenadora do Núcleo de Ações Pedagógicas Integradas) apud CGN, o número de adolescentes grávidas registrados na rede pública de saúde, no período de junho de 2011 a junho de 2012, foi de 786 casos - 744 casos entre jovens de 15 a 19 anos e, 42 casos na faixa etária de 10 a 14 anos. Considerando que, nesse período, foram totalizadas 3.436 gestantes, aproximadamente $21 \%$ delas são adolescentes. No entanto, como consta na notícia, "estima-se que os números reais sejam três vezes maiores, incluindo casos de aborto e outras situações não registradas em hospitais particulares de saúde".

Esses dados concordam com a pesquisa feita por Tavares et al. no Hospital Universitário do Oeste do Paraná (HUOP) localizado em Cascavel. O autor evidenciou alto número de partos em adolescentes $(22,6 \%)$ em uma amostra composta por puérperas atendidas na Maternidade do HUOP em outubro de 2008.

As consequências que, segundo Cardoso (2004), podem ocorrer de uma gravidez precoce incluem perda das oportunidades educacionais e de trabalho, diminuição da qualidade de vida, ausência de um convívio familiar equilibrado, falta de apoio do parceiro, críticas da sociedade, efeitos psicológicos, e também efeitos biológicos - o corpo da adolescente ainda não está pronto para ter uma gestação, pois, como afirma Oliveira (1998), "as consequências perversas de uma gravidez na adolescência se fazem sentir tanto na morbidade/mortalidade de mãe e bebê quanto nos impactos econômico, educacional-escolar e social".

Além da gravidez precoce, a falta de discussão da sexualidade contribui, também, para o aumento da disseminação das DST. Essas, antigamente conhecidas como doenças venéreas, são um grupo variável de infecções causadas por agentes microbianos, biologicamente diferentes, mas mantém em comum a forma de transmissão (sexual). Há diversos tipos de DST, que ao total somam mais de dez. Para o leigo não é necessário distinguir os sintomas 
que caracterizam as diferentes DST, mas é fundamental conhecer quais são para procurar atendimento na presença de algum.

Como se infere do Boletim Epidemiológico de 2011, o número de casos de HIV em adolescentes entre 15 aos 24 anos elevou-se. A taxa de incidência de HIV em jovens nessa faixa etária vem subindo desde 2006, quando era de 8,1 e, em 2011, passou a ser de 9,5, para cada 100 mil habitantes. É válido ressaltar que "As regiões Sul e Sudeste concentram $83 \%$ do total de casos de aids notificados, desde o início da epidemia" (Boletim Epidemiológico 2011).

Em Cascavel, segundo o DATASUS, no período de 1985 a 2011, foram notificados 870 casos de AIDS, sendo que, por apresentar mais de 50 casos de AIDS entre 2002 e 2006, o município pode ser considerado como de grande magnitude de epidemia, como afirma Horvath (2011). Apesar de os números não serem muito expressivos, demandam grande atenção devido tanto ao impacto socioeconômico como individual da doença.

Nota-se isso ao analisar relatórios do Ministério Público, do Ministério da Saúde e do site Contas Abertas. Os valores gastos na prevenção e combate ao HIV e seus agravos, entre 2007 e 2011 fora de cerca de 5,4 bilhões de reais, sendo que o valor vem aumentando ano após ano. Somente em 2011 foram despendidos 1,2 bilhões.

Frente ao grande número de adolescentes grávidas, ao imenso número de portadores de HIV não diagnosticados e sem tratamento, ao ainda crescente número de contágios por DST, ao enorme preconceito ainda existente na sociedade sobre os diversos assuntos relacionados à sexualidade e a incapacidade dos pais e das escolas em tratarem esse assunto com naturalidade e segurança surgiu o projeto de extensão chamado de LOGOS - Conhecer para prevenir.

Tal projeto de extensão visa informar alunos do ensino médio, tanto da rede pública quanto da privada, sobre prevenção de DST/AIDS, gravidez e discutir a sexualidade a partir da visão holística do ser humano para que sejam destruídos quaisquer mitos e crendices sexuais que possam existir.

Além disso, a atividade ainda tem como objetivo apresentar os principais métodos contraceptivos assim como discutir a eficácia, custo, acesso, vantagens, desvantagens e crendices em relação a sua interferência na sexualidade, além de esclarecer sobre o uso correto dos mesmos.

Ainda, figura entre as metas do projeto a transmissão de conteúdo científico básico sobre DST/AIDS - com enfoque aos agentes patógenos, mecanismos de transmissão, sintomas 
das doenças, possíveis consequências e principalmente, métodos para prevenção - e a descrição da anatomia e fisiologia da sexualidade e da reprodução, relacionando-as com os seus aspectos biopsicossociais. E, por último, mas não menos importante, o LOGOS visa o estreitamento de relações entre a UNIOESTE (Universidade Estadual do Oeste do Paraná) e as escolas públicas estaduais da rede de ensino médio.

Vale ressaltar que alguns objetivos desse projeto de extensão como o combate a AIDS, a redução da mortalidade infantil e o melhoramento da saúde das gestantes figuram entre os oito objetivos do milênio propostos pelas Organizações das Nações Unidas - ONU. Esta Organização lançou recentemente uma campanha mundial com o intuito de extinguir, até 2015, a transmissão vertical do HIV (Vírus da Imunodeficiência Humana).

\section{MATERIAL E MÉTODOS}

A cada ano, as atividades do projeto iniciam-se com a apresentação e discussão das dinâmicas e demais atividades com os ingressantes do curso de Medicina no campus de Cascavel. Após os alunos interessados em fazer parte do projeto alistam-se passando seus nomes para os integrantes do projeto, conforme disponibilidade de horário do acadêmico. Antes de serem integrados legalmente no projeto, os ingressantes interessados devem acompanhar, ao menos, uma palestra com os alunos já presentes no projeto.

Depois de feito o acompanhamento, inicia-se a etapa preparatória dos alunos a qual consiste na realização de levantamento bibliográfico, no acompanhamento de aula sobre estratégias didático-pedagógicas ministrada pela orientadora e na preparação para educação sexual centrada no adolescente ofertada pelo Centro Especializado em Doenças InfectoParasitárias - CEDIP e ministrada por duas psicólogas que trabalham a sexualidade em toda a sua abrangência, desde aspectos relacionados ao preconceito até as diversas doenças que possuem transmissão sexual.

A etapa preparatória pela qual passam todos os ingressantes do projeto Logos é de fundamental importância, pois é o momento no qual se adquirem novos conhecimentos necessários para a posterior condução do projeto. O levantamento bibliográfico propicia o entendimento da anatomia e fisiologia da reprodução, assim como das patologias relacionadas às diferentes práticas sexuais. A aula sobre estratégias didático-pedagógicas ministrada pela orientadora proporciona múltiplos métodos e técnicas de ensino, focado para adolescentes, que serão utilizados durante a aplicação do projeto. E, para encerramento dessa etapa 
preparatória, ocorre a preparação para educação sexual, ofertada pelo CEDIP. Tal capacitação é de suma importância, pois a questão da sexualidade causa ansiedades até mesmo para os extensionistas devido a sua importância e aos tabus e mistérios que normalmente se criam em torno do tema. Como cita Cardoso (2004, p.28),

\begin{abstract}
A tarefa da orientação sexual é árdua, assim como todo o trabalho educativo. Porém, além de todas as dificuldades previstas ainda nos deparamos com preconceitos e resistências. "Essas resistências podem ser observadas até mesmo dentro de nós. É um susto, temos que nos dar conta de que fomos educados dentro de uma sociedade patriarcal, cheia de tabus, de desinformação e medo de mudanças" (Suplicy, 1994, p.4).
\end{abstract}

Ainda, sobre sexualidade, Costa (1986, p.7) afirma,

Dentro das próprias universidades, o assunto ainda é tratado de maneira superficial, demonstrando que tanto médicos como psicólogos e professores não conseguiram, em grande parte, superar os próprios medos, que carregam como qualquer pessoa comum.

Assim, a preparação pelo CEDIP permite que as questões ligadas ao desenvolvimento emocional e sexual sejam abordadas, pelos extensionistas, de forma clara e sem falsos pudores, possibilitando aos ouvintes refletir não só sobre sua própria vida íntima, como também sobre a importância de sua relação com o outro e com o mundo. Sendo assim, essa capacitação é fundamental para se alcançar o objetivo de um trabalho de educação e orientação sexual que é permitir que os alunos entendam a sexualidade como um aspecto positivo e natural da vida humana, proporcionando livres discussões de normas e padrões de comportamento em relação ao sexo, para que, a partir de um pensamento crítico, elaborem seus próprios valores.

Em seguida, os acadêmicos preparam sua própria palestra de acordo com os tópicos estabelecidos pelo grupo e apresentam para os demais colegas. Neste momento, os docentes e participantes podem sugerir melhorias tanto na didática quanto no conteúdo e forma da palestra, pois a palestra é sempre passível de sofrer alterações, até mesmo após as primeiras apresentações nas escolas. Assim, após uma boa preparação, os acadêmicos seguem com as palestras nas escolas.

A divulgação das palestras é realizada através de cartas e e-mail endereçados às escolas de Cascavel. Já, o agendamento das palestras fica sob a responsabilidade do NEI 
(Núcleo de Estudos Interdisciplinares) do campus de Cascavel e de aluno responsável indicado pela orientadora.

Ao menos uma vez a cada quinze dias são realizadas reuniões com todos os integrantes do projeto para: atualização de dados sobre os temas; troca de experiências entre os palestrantes e proposta de mudanças ou novas dinâmicas; planejamento das próximas palestras de acordo com as principais dúvidas levantadas e; analisar as respostas dos questionários e propor meios para corrigir falhas de forma que a informação melhore o processo ensino-aprendizagem.

As palestras são realizadas nas dependências das escolas de ensino médio de Cascavel e seguem uma programação determinada anteriormente no preparo das mesmas. As atividades foram montadas para serem executadas em um tempo médio de duas horas. Elas iniciam-se sempre com a apresentação pessoal dos acadêmicos-monitores e com uma explanação geral dos temas que são abordados.

Após, são lidas as "Regras de Convivência" (conforme apêndice I), tendo por objetivo organizar e permitir o bom andamento das demais oficinas. Logo após distribuem-se pedaços de papéis para que os alunos escrevam dúvidas que possam surgir durante a palestra que os embaraçariam de perguntar frente a toda a classe. Essas dúvidas são recolhidas no final da palestra na "Caixa de Perguntas" e respondidas. É essencial que todos depositem o papel na “Caixa de Perguntas", mesmo não tendo nada escrito. Essa dinâmica possibilita que o aluno pergunte sem ser identificado. Permitindo o questionamento de assuntos, principalmente, pessoais, que abertamente o aluno não faria seja por vergonha ou qualquer outro motivo.

Em seguida, é aplicada a dinâmica dos "Sinônimos", na qual é solicitado aos alunos que sugiram cinco sinônimos utilizados por eles no dia-a-dia para as palavras: pênis, vagina, sexo, sêmen e masturbação. Os sinônimos são escritos no quadro e é feita a votação para escolha do sinônimo que melhor represente as palavras mencionadas acima. Os sinônimos escolhidos serão utilizados durante todo o desenvolvimento do projeto naquele colégio, tanto para os extensionistas quanto para os discentes. A finalidade é fazer com que os participantes sintam-se mais familiarizados com os palestrantes através do uso de um vocabulário menos formal e que está presente no dia-a-dia dos alunos-alvo do projeto. Dessa forma, os alunos se sentem mais a vontade para fazer suas perguntas e se mantêm atentos à palestra para que possam corrigir caso algum dos palestrantes não use o sinônimo escolhido. Como cita Gir et al (apud BARTSCHER, 2000), a parte sexual referente à história de vida do indivíduo é vista como um invasão de privacidade. Para que essa visão seja amenizada, ela sugere alguns 
aspectos práticos para que não traumatize os jovens adolescentes e que eles não bloqueiem o diálogo. Neste sentido, a autora propõe que devemos começar sempre com tópicos mais gerais e progredir para os mais pessoais, evitando uma linguagem vaga e termos não específicos, utilizando-se de termos mais familiares ao indivíduo.

A próxima dinâmica é chamada de "Concordo/Discordo". Nessa atividade, é separada a sala em duas metades, lê-se uma afirmação e se os alunos concordam devem mover-se para a direita, caso contrário vão para esquerda. Utiliza-se uma linguagem acessível a fim de facilitar a compreensão para os alunos do ensino médio. As afirmações foram elaboradas de acordo com o que se desejava discutir. Após a dinâmica, eram discutidas as afirmações e dirimidas as dúvidas que surgiam durante a mesma. Ainda, aproveitando-se do ensejo, apresentam-se as principais DST (sinais, sintomas e formas de contágio) e faz-se a demonstração e explanação sobre funcionamento, eficácia, vantagens e desvantagens dos materiais contraceptivos, como DIU, pílula, diafragma e outros, excetuando-se a camisinha (que é discutida posteriormente). Esta dinâmica visa identificar mitos, tabus, crendices e o conhecimento prévio dos temas abordados, os quais são divididos em três principais: sexualidade e preconceito; contracepção e; DST. A partir das dúvidas surgidas durante a aplicação e discussão da atividade, a palestra é direcionada para algum dos três grandes temas. No entanto, vale ressaltar, que todos os assuntos são discutidos, apesar do foco em apenas um deles.

Depois do "Concordo/Discordo", aplica-se a dinâmica da "Mão e Luva", contando com a participação de dois alunos. No primeiro voluntário é passada tinta sobre a mão direita, calça-se uma luva na mão besuntada e em seguida pede-se para cumprimentar todos os colegas de classe que se dispuser a "tal gentileza". O segundo aluno é submetido às mesmas condições; entretanto não é utilizada uma luva. Antes do início dessa dinâmica é disposta uma caixa de luvas em uma mesa visível para todos os alunos. O objetivo desta atividade é mostrar de forma comparativa que o uso da camisinha (simbolizada pela luva), protege da transmissão do HIV (representado pela tinta), pois aquele que calçava a luva ficou protegido da tinta mesmo havendo o contato. A caixa de luvas que é disposta visivelmente para todos os alunos procura representar que o adolescente deve ter um papel ativo na prevenção das DST, ou seja, ele deve lembrar-se do preservativo e fazer o uso do mesmo. Como afirma Cardoso (2004, p.26): "É no período da adolescência que o jovem sente aflorar seus impulsos sexuais, levando em consideração apenas o momento e esquecendo-se da responsabilidade que mais tarde terá que assumir. Um exemplo disso é o jovem louco para perder sua virgindade, mas 
não carrega uma camisinha no bolso.”. Sendo assim, a atitude esperada na atividade era que o adolescente fosse buscar a luva para cumprimentar o seu colega que estava com a mão sem luva e besuntada com tinta.

Terminada a "Mão e Luva", segue-se com a próxima dinâmica que é chamada "Texto sobre a AIDS". Para a realização dessa atividade é propiciado um ambiente no qual seja possível uma maior concentração. Com a iluminação da sala desligada, pede-se para que os alunos baixem suas cabeças, fechem os olhos e imaginem-se no lugar do narrador. Uma faixa musical tranquila é posta e, então, inicia-se a leitura pausada do texto (conforme apêndice II). Imediatamente após o término da leitura, a iluminação da sala é ligada e inicia-se a discussão do texto. Essa atividade busca - através da leitura do texto, no qual o jovem descobre que seu companheiro é soropositivo - destruir o pensamento mágico comum entre os adolescentes de que são invulneráveis (representada pela máxima "isto nunca vai acontecer comigo") e, concomitantemente, discutir as reações deles próprios em frente àquela notícia, abordando assim, o preconceito contra o portador do HIV. São discutidos, também, vários outros assuntos, como por exemplo, caso não tivesse se prevenido quais os procedimentos que se deve tomar - aproveitando o ensejo para informar sobre o CEDIP - e diversas outras dúvidas que, por ventura, puderam surgir durante a explicação.

Após o debate da atividade anterior, inicia-se a dinâmica da "Sensibilidade". Para sua execução é solicitado um voluntário entre os alunos. Na mão desse jovem é colocado um preservativo que é esticado até parte do antebraço, de modo a, primeiramente, mostrar a resistência e elasticidade do material (antes, qualquer adorno é retirado da mão/braço para evitar perfurações e prejuízos no andamento da dinâmica). Em seguida, instrui-se para que o participante olhe para o lado oposto ao que o realizador da dinâmica se encontra, de modo que este fique fora do campo de visão do voluntário, assim como o membro protegido pelo preservativo. Feito isso, são proporcionadas algumas sensações táteis no antebraço revestido e pede-se para que identifique a ação, assim como a temperatura e textura sentidas. Entre as ações propiciadas estão a aspersão com água, um sopro, uma lambida, e, por último, o espalhamento de uma tinta pastosa. O objetivo é demonstrar que o uso do preservativo não implica na perda do prazer durante a relação sexual. Essa perda de sensibilidade é utilizada por muitos adolescentes como argumento para defenderem a não utilização da camisinha. Podemos perceber isso nas palavras de Lopes (1993, p.40): “Alguns adolescentes alegam uma diminuição do prazer sexual com seu uso, com a velha história de comparar o uso da camisinha ao de chupar bala com papel", assim como afirma Cardoso (2004, p.80): "Já a 
camisinha masculina é de fácil acesso e um dos métodos mais eficazes contra uma gravidez indesejada, embora muitos jovens não a utilizem de forma correta e alguns ainda acreditem que a mesma pode comprometer o prazer no momento da relação sexual”. Sendo assim, faz-se necessária a dinâmica da "Sensibilidade" para destruir os conceitos errôneos que os jovens possuem sobre o preservativo e estimular a utilização do mesmo.

E, por último, é realizada dinâmica denominada "Camisinha: como usar", que tem como meta demonstrar a forma de utilização correta tanto do preservativo masculino quanto do feminino, pois como citado anteriormente, Cardoso (2004), muitos jovens não utilizam o preservativo de forma correta, comprometendo a tão sonhada proteção que desejavam. Tal atividade é dividida em duas partes, sendo a demonstração e discussão do uso do preservativo masculino, a primeira parte, e do feminino, a segunda. Ambas as partes contam com a participação de um aluno voluntário. Utilizando-se uma prótese peniana de borracha, na primeira parte, e um modelo pélvico do aparelho reprodutor feminino, na segunda, pede-se ao aluno para vestir uma camisinha na prótese/modelo pélvico da maneira que lhe for adequado. Fica por conta de o voluntário averiguar quaisquer questões referentes à viabilidade do preservativo, haja vista que este era fornecido ao estudante em uma embalagem tradicional podendo estar em condições inapropriadas de uso. Após o estudante vestir a prótese/modelo pélvico ao modo que achou conveniente, os demais alunos da sala são, então, questionados acerca da maneira pela qual o colega voluntário usou para colocar o preservativo no projétil peniano/modelo pélvico. Se houvesse opiniões divergentes entre os estudantes, iniciava-se uma pequena discussão sobre a maneira como os demais alunos achavam que deveria ser colocada a camisinha, indicando os possíveis erros cometidos pelo voluntário. Depois disso, caso o preservativo tenha sido vestido inadequadamente, era ensinado detalhadamente aos estudantes a maneira correta de usá-lo; inclusive de avaliar sua viabilidade, antes mesmo de abrir a embalagem.

Excetuando-se a abstinência sexual e os modos de transmissão vertical e sanguíneo, o uso do preservativo é o único meio capaz de prevenir múltiplas doenças transmitidas sexualmente - seja da modalidade genital, anal ou oral - e também a gravidez. Logo, saber avaliar a viabilidade de um preservativo e usá-lo adequadamente torna-se imprescindível.

No término dessa dinâmica, ressaltavam-se alguns pontos básicos, como a incapacidade de se usar um preservativo mais de uma vez, abrir a embalagem apenas na hora do uso (no caso do masculino, pois o preservativo feminino pode ser colocado até oito horas antes da relação), e também a informação de que o uso de duas camisinhas não garante dupla 
proteção, mas sim aumenta consideravelmente os riscos de ruptura devido a força de atrito. Também é feita, ao final, uma comparação entre os preservativos masculino e feminino, de modo a ressaltar as vantagens e desvantagens de cada um.

Aproveitando-se da prótese peniana e do modelo pélvico feminino utilizados anteriormente, era feita uma explanação sobre a anatomia e fisiologia do aparelho reprodutor humano.

Por fim, é tomado tempo para dúvidas no final da oficina sobre qualquer assunto ligado a sexualidade que tenha sido discutido ou não e para distribuir folders educativos (fornecidos pelo CEDIP de Cascavel). Ainda, no início das atividades e antes do término das mesmas, foi aplicado um questionário (apêndice III) para verificar se o conteúdo ministrado foi compreendido pelos alunos e também para orientar mudanças pedagógicas no projeto, caso necessário.

\section{RESULTADOS E ANÁLISE}

A análise de 83 questionários (apêndice III) aplicados antes e após a oficina no ano de 2011 revelou uma evolução no conhecimento e diminuição do preconceito de grande parte dos alunos pesquisados, que pode ser percebido pelo aumento no número de respostas corretas e redução no de incorretas (ilustração 1).

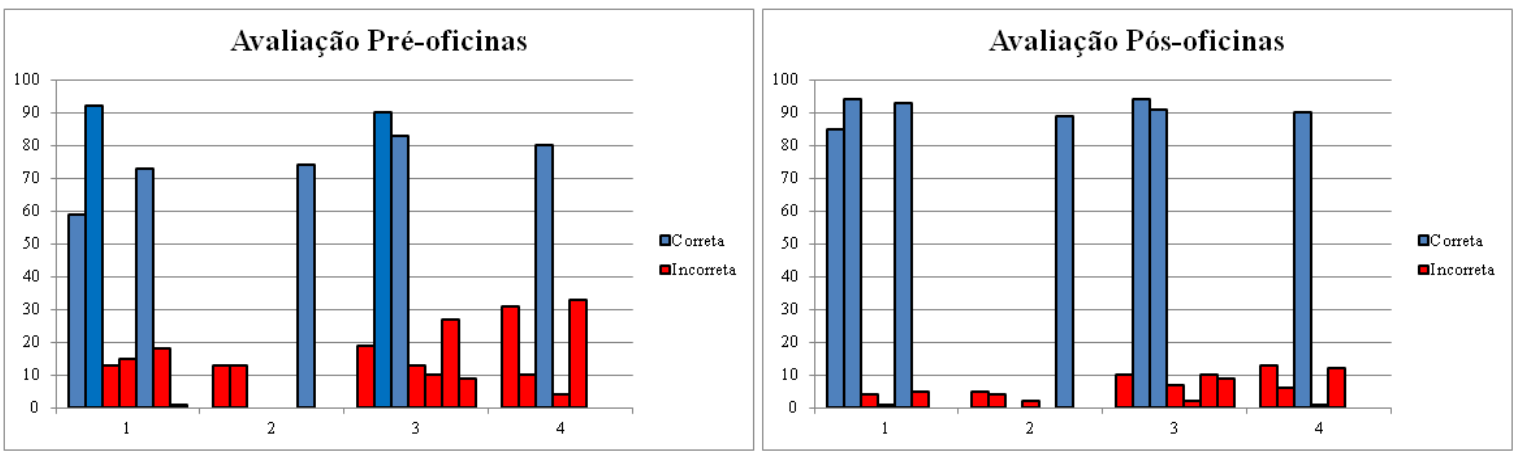

Figura 1 - Avaliação do aprendizado dos alunos antes e depois das oficinas. Fonte: Elaborado pelos autores.

Na primeira pergunta foi constatado que menos de $60 \%$ dos alunos assinalaram as três alternativas corretas sobre as maneiras de transmissão do HIV. Isso retrata que, mesmo com todo o acesso a informação que os jovens atualmente possuem, uma porcentagem baixa dos pesquisados conhecia as vias de contágio. Assim sendo, ficariam mais expostos à contaminação pelo vírus. As formas de transmissão corretas mais assinaladas foram o sexo 
vaginal sem camisinha (92\%) o compartilhamento de seringas $(73 \%)$, sendo que a alternativa correta menos marcada foi a transmissão através do sexo oral sem camisinha (59\%).

Alguns alunos, também, assinalaram alternativas incorretas. A alternativa incorreta menos assinalada foi a transmissão do HIV através do sexo anal com camisinha (1\%), sendo que as outras alternativas incorretas tiveram um percentual maior de marcações, beijo na boca (13\%), compartilhamento de banheiro com um portador do vírus (15\%) e beber no mesmo copo que um portador do vírus (18\%). Pode-se perceber, de forma clara, a carência de informação desses alunos do Ensino Médio, pois o índice de marcação de alternativas incorretas foi muito alto considerando-se que as alternativas envolvem conceitos básicos sobre a transmissão do HIV.

Após a apresentação das dinâmicas verificou-se que o índice de acerto subiu para 85\%. Esse pode ser considerado baixo ainda, e pode indicar uma falha no momento da explanação sobre as formas de transmissão do vírus. Quando se observa o índice de assertivas marcadas incorretamente, evidencia-se que houve considerável queda, ajustando-se conceitos errôneos como: beber no mesmo copo, compartilhar o banheiro e beijo na boca transmitem o HIV.

Em relação a segunda questão, que se referia a quem tinha mais chances de contrair o HIV, houve grande percentual de acertos (74\% - "qualquer pessoa tem a mesma chance de contrair o HIV se fizer sexo sem camisinha"). No entanto, ainda foram constatadas algumas respostas erradas, sendo que $13 \%$ dos pesquisados acreditavam que homossexuais tinham mais chances de contrair o vírus e $13 \%$ dos pesquisados pensavam o mesmo sobre travestis. Podemos perceber, então, que ainda sobrevivem conceitos que apenas o homossexual ou travesti contraem HIV. Isso, além de poder gerar preconceito, pode expor o jovem a comportamentos de risco por acreditar que está "protegido" da infecção pelo vírus. Vale ressaltar que duas alternativas incorretas (homens heterossexuais e mulheres heterossexuais) não tiveram nenhuma marcação, o que pode sugerir falta de informação ou até mesmo um leve preconceito.

Nessa questão os dados mostram claramente a importância de se explicar adequadamente conceitos básicos e fundamentais aos jovens. O número de acertos, após a oficina, subiu de 74 para $89 \%$, e o erro, antes $13 \%$ tanto para homossexuais quanto para travestis declinou, respectivamente para 5 e $4 \%$.

$\mathrm{Na}$ terceira, pergunta que questionava sobre os métodos indicados para evitar contrair DST, havia duas respostas corretas. Menos de $80 \%$ dos alunos acertaram a questão 
completamente, $90 \%$ deles assinalaram a camisinha masculina como sendo um método para evitar contrair DST e apenas $83 \%$ afirmaram o mesmo sobre a camisinha feminina. Isso pode demonstrar a falta de conhecimento sobre o preservativo feminino, que apesar de menos difundido, possui importância visto algumas vantagens sobre o masculino. A distribuição das respostas incorretas foi a seguinte: pílula anticoncepcional 27\%; pílula do dia seguinte 19\%; coito interrompido 13\%; tabelinha $10 \%$ e DIU 9\%. Essas marcações demonstram a dificuldade que muitos jovens possuem ao diferenciar o conceito de métodos contraceptivos de métodos para evitar contrair DST, tornando indispensável a explicação sobre o assunto.

Após a aplicação do projeto, o número de acertos tanto considerando o uso de preservativo masculino quanto feminino como métodos de prevenção à DST elevou-se para mais de $90 \%$. Ao mesmo tempo, o número de erros diminui consideravelmente para todas as alternativas incorretas, sendo que o declínio mais expressivo foi da assertiva "pílula anticoncepcional" que reduziu de $27 \%$ para $10 \%$.

$\mathrm{Na}$ última questão havia apenas uma afirmação correta, mas os alunos podiam assinalar diversas alternativas. Novamente, a maioria (80\%) acertou a resposta ("a camisinha é o único método para evitar doenças transmitidas pelo sexo"). Esse percentual pode ser considerado baixo, pois se uma adolescente acredita que há outro método para evitar DST, ele pode estar propenso a comportamentos de risco, como fazer sexo sem preservativo. Mas, assim como antes, houve algumas marcações incorretas, sendo que as mais incorretamente assinaladas foram camisinha tira a sensibilidade (33\%) e homossexualidade e anormal (31\%), assim demonstrando que a dinâmica da "sensibilidade" é extremamente útil para desmistificar essa ideia. Não menos importantes, entretanto menos marcadas, foram as afirmações masturbação provoca espinhas (10\%) e só os homens se masturbam (4\%).

Verificou-se que o índice de acerto elevou-se para 90\% após a apresentação das dinâmicas. Tendo, também, uma notável diminuição nas marcações incorretas. As alternativas que melhor representam essa redução foram "camisinha tira a sensibilidade", que caiu de 33\% para $13 \%$, e "homossexualidade é anormal", reduzindo de $31 \%$ para $13 \%$. As demais afirmativas também apresentaram redução, no entanto, menos acentuada que as citadas anteriormente.

Junto com as perguntas do questionário pós-oficina foram realizadas mais 3 questões pessoais sobre o projeto. A primeira foi: “Quanto você aprendeu com o projeto?”. A grande maioria (86\%) assinalou a opção "Muito" e apenas 14\% a segunda opção, "Mais ou menos". Não houve sequer uma marcação nos campos "Pouco" e "Nada". Mais uma vez, fica 
estabelecido uma reciprocidade de conhecimento, uma deposição de confiança que extrapola os limites daquele aprendizado que o aluno não participa, não dinâmico.

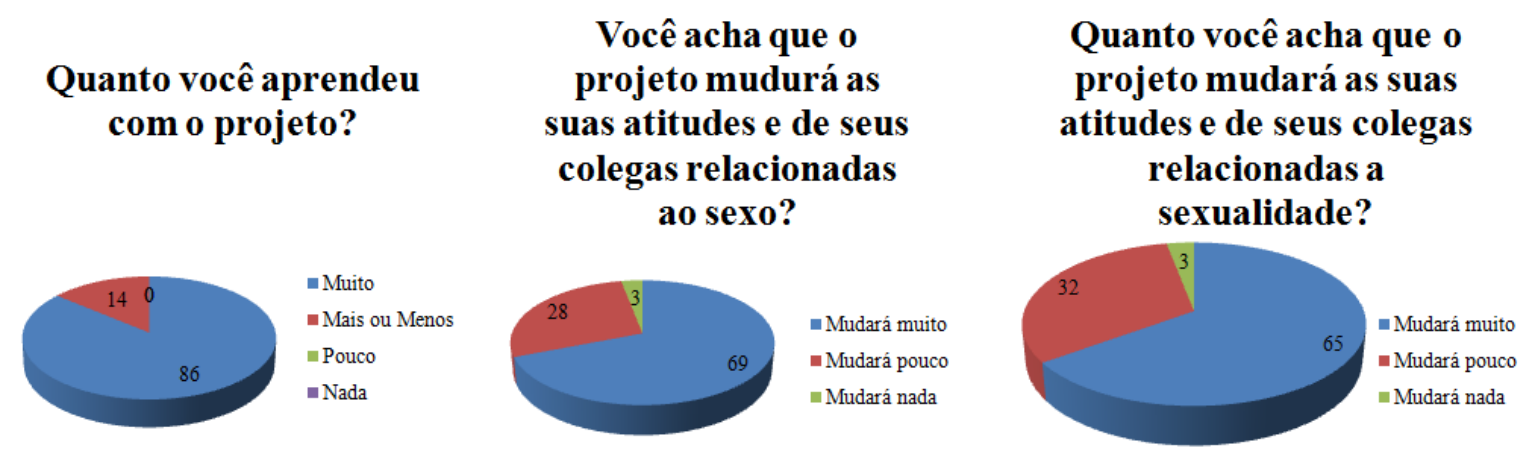

Figura 2 - Avaliação do projeto LOGOS pelos alunos do Ensino Médio.

Fonte: Elaborado pelos autores.

Um fato que demanda um pouco de cuidado é que ao se questionar "Você acha que o projeto mudará as suas atitudes e de seus colegas relacionadas ao sexo?”, 28\% optaram pelo "mudará pouco". Embora 69\% acreditem que "mudará muito", aqueles que marcaram "mudará pouco" merecem mais atenção, uma vez que, pode-se inferir que escolher essa alternativa foi devido à sua descrença na mudança de atitude dos colegas.

Praticamente o mesmo pode se deduzir da última indagação: "Você acha que o projeto mudará as suas atitudes e de seus colegas relacionadas à sexualidade?" 65\% marcaram que "mudará muito" e 32\% afirmaram que "mudará pouco". Essa questão ainda tem o agravante do preconceito, que fica subentendido no grande número de marcantes da segunda opção.

Entretanto, como percebido por essas últimas indagações, a maioria das pessoas atingidas pelo projeto acredita que aprendeu muito e que de alguma forma o conhecimento adquirido poderá modificar suas atitudes frente à sexualidade e ao sexo, diminuindo-se seus preconceitos e evitando comportamentos de risco.

\section{CONSIDERAÇÕES FINAIS}

Embora o Ministério da saúde brasileiro tenha investido maciçamente em campanhas de cunho preventista e eliminatório das infecções de DST, a população parece ter muitas dúvidas.

O Projeto LOGOS agiu presencialmente nas salas de aula, o público objetivado sempre foi atingido integralmente, transmitindo-se o conhecimento científico de forma clara e dinâmica, acerca dos diversos assuntos mencionados anteriormente. 
Pelos dados obtidos pode-se observar que se alcançaram mudanças comportamentais para prevenir DST/HIV, na transmissão vertical, promoção do uso de preservativos, redução de riscos em usuários de drogas injetáveis (UDI), aconselhamento sobre o serviço de testagem (CEDIP), contraceptivos, fisiopatologia das principais DST e fisiologia básica dos Sistemas Reprodutores.

O Projeto possibilitou a integração da Universidade com a comunidade, respaldando um dentre os três pilares de uma Universidade Pública, que representa a extensão. Esta visa o alcance e elucidação de problemas sociais tanto em nível individual quanto coletivo, difundindo-se o conhecimento acadêmico e social de maneira bidirecional e priorizando as necessidades emergentes da sociedade.

É unânime o parecer de que essa atividade contribuiu de forma essencial para a formação acadêmica e profissional dos extensionistas, pois, foi constatada uma significativa evolução na desenvoltura dos acadêmicos demonstrada ao longo das palestras. Assim sendo, o projeto além de ter contribuído para a divulgação científica, proporcionou uma experiência para os palestrantes que desenvolveram a capacidade de falar em público, fundamental para o exercício da profissão e também da docência.

Apesar de todo o conhecimento científico passado, foi de fundamental importância a discussão da sexualidade em seu contexto mais amplo para permitir que os adolescentes entendessem sua sexualidade como um aspecto positivo e natural da vida humana. E para proporcionar livres discussões de normas e padrões de comportamento em relação ao sexo. Os debates de atitudes pessoais frente à própria sexualidade são um ensinamento concreto que deve fazer com que os alunos compreendam por que as coisas são como são e como vieram a se tornar assim; tornar o familiar estranho e o estranho familiar.

Desse modo, os jovens mais informados a respeito de sua sexualidade terão melhores condições de superar problemas cotidianos relacionados a esse assunto e estarão abertos ao diálogo, participando ativamente do processo de educação sexual, desenvolvendo uma vida mais saudável, juntamente com a família, escola e sociedade.

\section{REFERÊNCIAS}

BÉRIA, J.; OLIVEIRA O. M. F.; CARRET M. L. V. Adolescentes e DST/AIDS: pesquisa formativa em um estudo de intervenção. In: Béria J. Ficar, transar... a sexualidade do adolescente em tempos de AIDS. Porto Alegre: Tomo Editorial; p.111-25, 1998. 
BERTOLDI, M. P.; PESSOA, O. F. Sexo e vida: o universo da ciência. 8 ed. São Paulo: Scipione, 1997.

BRASIL. INSTITUTO BRASILEIRO DE GEOGRAFIA E ESTATÍSTICA. Censo 2010. Disponível em:〈http://www.ibge.gov.br/home/>. Acesso em: 14 mar. 2012.

BRASIL. MINISTÉRIO DA SAÚDE. Aids no Brasil. Disponível em: <http://www.aids.gov.br/pagina/aids-no-brasil >. Acesso em: 04 maio 2012.

BRASIL. MINISTÉRIO DA SÁUDE. Boletim Epidemiológico 2011. Disponível em: <http://www.aids.gov.br/publicacao/2011/boletim_epidemiologico_2011>. Acesso em: 04 abr. 2012.

BRASIL. MINISTÉRIO DA SAÚDE. DEPARTAMENTO DE INFORMÁTICA DO SUS. Doenças de Notificação - Aids desde 1980. Disponível em: <http://www2.datasus.gov.br/DATASUS/index.php?area=0203 >. Acesso em: 20 maio 2012.

CANO, M.A.T.; FERRIANI, M.das G.C. Sexualidade na adolescência: um estudo bibliográfico. Rev.latinoam.enfermagem, Ribeirão Preto, v. 8, n. 2, p. 18-24, abr., 2000.

CARDOSO, Gessi Maria (org). Adolescente: limites e consequências. Cascavel, PR: Editora Coluna do Saber, 2004.

CGN. Cascavel, PR. 782 casos de adolescentes grávidas. Disponível em: <http://cgn.uol.com.br/noticia/29524/em-um-ano-782-casos-de-adolescente-gravidas >.

Acesso em: 20 ago. 2012.

COSTA, Moacir. Sexualidade na adolescência, dilemas e crescimento. $11^{\mathrm{a}}$ Ed. Porto Alegre: L\&Pm, 1997.

FLEMING, Sílvia Falleiros (org). Manual para elaboração de trabalhos científicos, redação oficial e comercial. Cascavel, PR: Coluna do Saber, 2005.

GIR, E.; NOGUEIRA, M.S.; PELÁ, N.T.R. Sexualidade humana na formação do enfermeiro. Rev.latinoam.enfermagem, Ribeirão Preto, v. 8, n. 2, p. 33-40, abr., 2000. 
GIROUX, A. Henry; SIMON, Roger. Cultura popular e pedagogia crítica: a vida cotidiana como base para o conhecimento. In: SILVA, T. T., MOREIRA, A. F. B. (Org.). Currículo, cultura e sociedade. São Paulo: Cortez, 1994. p. 93-124.

HORVATH, Josana Aparecida Dranka. A epidemia de aids no município de Cascavel PR. São Paulo, 2011. 43f. Monografia (Especialização em Prevenção ao HIV/Aids no quadro da Vulnerabilidade e dos Direitos Humanos). Faculdade de Medicina da Universidade de São Paulo.

JHOJE. Cascavel, PR. Mesmo informadas, jovens ainda são 20\% das grávidas. Disponível em: <http://www.jhoje.com.br/Paginas/20120815/local.pdf>. Acesso em: 21 ago. 2012.

LOPES, Gerson. Sexualidade Humana. Rio de Janeiro: MEDSI, 1993.

MARTINS, L. B. M. et al. Fatores associados ao uso de preservativo masculino e ao conhecimento sobre DST/AIDS em adolescentes de escolas públicas e privadas do Município de São Paulo, Brasil.Cad. Saúde Pública, v. 22, n. 2, p. 315-323, fev., 2006.

O VOLUNTARIADO E OS OBJETIVOS DO MILENNIO DA ONU. 8 jeitos de mudar o mundo. Disponível em: 〈http://www.objetivosdomilenio.org.br/>. Acesso em: 20 mar. 2012.

OLIVEIRA, Maria Waldenez De. Gravidez na adolescência: Dimensões do problema.Cad. CEDES, Campinas, v. 19, n. 45, jul., 1998.

ORGANIZAÇÃO DAS NAÇÕES UNIDAS. Relatório do UNICEF revela situação de adolescentes no Brasil. Disponível em: <http://www.onu.org.br/relatorio-do-unicef-revelasituacao-de-adolescentes-no-brasil/> . Acesso em: 24 mar. 2012.

ORGANIZACIÓN MUNDIAL DE LA SALUD (OMS). Problemas de salud de la adolescência. Série de Informes técnicos, Geneva: OMS, 1965.

OSÓRIO, Luiz Carlos. Adolescente Hoje. Porto Alegre: Artes Médicas, 1989.

OUTEIRAL, José Ottoni. Adolescer: Estudos Sobre Adolescência. Porto Alegre: Artes Médicas Sul, 1994.

PINHEIRO, Verônica De Souza. Repensando a maternidade na Adolescência. Estudos de Psicologia, Natal, v. 5, n. 1, p. 243-251, 2000. Universidade Federal do Rio Grande do Norte. 
Disponível em: 〈http://www.scielo.br/pdf/epsic/v5n1/a11v05n1.pdf>. Acesso em: 21 ago. 2012.

PORTAL DO MUNICÍPIO DE CASCAVEL. Cedip trabalha prevenção e preconceito contra Aids. Disponível em: <http://www.cascavel.pr.gov.br/noticia.php?id=18313 >. Acesso em: 10 maio 2012.

PUPO, Lígia Rivero. Aconselhamento em DST/aids: uma análise crítica de sua origem histórica e conceitual e de sua fundamentação teórica. São Paulo, 2007. 247 f. Dissertação (Mestrado em Ciências). Faculdade de Medicina da Universidade de São Paulo.

REICH, Wilhelm. A revolução sexual. $8^{\mathrm{a}}$ Ed. Tradução: Ary Blaustein. Rio de Janeiro: Editora Guanabara, 1988.

SUGAR, Max. Adolescência Atípica e Sexualidade; Tradução: Ana Maria Mayer Singule. Porto Alegre: Artes Médicas, 1992.

TAVARES, Keila Okuda et al. Perfil de puérperas adolescentes atendidas em um hospital ensino no sul do país.ActaScientiarum, Health Sciences, Maringá, v. 34, n. 1, p. 9-15, janjun., 2012. 


\section{APÊNDICE I - Regras de Convivência}

OUVIR OS OUTROS PARA SER ESCUTADO DEPOIS;

NÃO ZOMBAR DAS PERGUNTAS DOS COLEGAS;

TODA PERGUNTA É BEM VINDA;

É NORMAL TER VERGONHA, TODOS TÊM;

É NORMAL NÃO SABER ALGUMAS RESPOSTAS, NÍNGUEM SABE TUDO;

NÃO SE DEVE FALAR ALGO QUE OFENDA OUTROS

PODEMOS FALAR SOBRE O QUE APRENDEMOS DEPOIS, MAS NUNCA USAR AS

PERGUNTAS DOS OUTROS PARA FAZER FOFOCAS;

\section{APÊNDICE II - Texto da AIDS}

"Imagine que em um dia qualquer você conhece alguém que the desperta um interesse surpreendente... uma pessoa que the vai cativando aos poucos... alguém com quem você poderia ficar uma tarde toda sozinho, fazer nada, ao lado dela, pois só de ficar junto dessa pessoa, bastaria... é alguém que sorri com os olhos... e olha de um jeito todo especial... você tem absoluta certeza de que é a pessoa com a qual sonhou a vida inteira... aquela que the entende e escuta... que sorri com você... e tenta consolar quando você está triste...

De repente vocês vão ficando tão próximos que fica impossível estar perto sem ficar juntos... Então rola o primeiro beijo... que de tão esperado parece passar um filme em sua cabeça... Você lembra-se dos momentos que tiveram juntos... que você desejava tanto sentir esses lábios.... esse cheiro... e subitamente, tudo que você ficava imaginando estava acontecendo... a espera então tornou aquele momento melhor ainda... depois de algumas vezes juntos vocês começam a namorar... e cada dia que passa parece que você quer sentir essa pessoa mais perto de você... Quer beijá-la mais... sentir... sua pele... e sentir sua respiração... Abraçá-la... Sentir seu cheiro sentir-se envolvido de verdade.... e esse dia começa acontecer... vocês estão em um lugar maravilhoso... um clima envolvente... nada parece atrapalhar... ninguém... vocês estão sozinhos... e aquele beijo começa a se tornar mais intenso, apaixonado, você sente-se tão leve... essa pessoa,cuidadosamente, desliza as mãos nos seus cabelos, acaricia seu rosto... seu corpo... você está tão envolvido...o momento toma conta de você... e essa pessoa diz que tem algo para the dizer e olha nos olhos... profundamente... de um jeito que the estremece todo e fala: tenho algo muito importante para dizer: EU TENHO AIDS!" 


\section{APÊNDICE III - Questionários Pré e Pós-oficina}

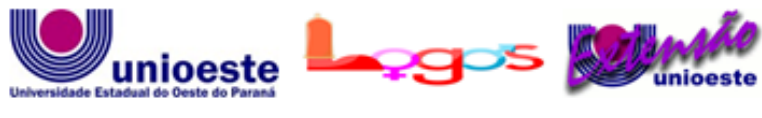

PROJETO LOGOS - Avaliação dos ahunos pré-oficinas

Colégio:

Serie

1) Assinale somente as maneiras em que se transmite o vinu da AIDS: (Pode assinalas várias altemativas)

a. Sexo oral SEM camisinha

b. Sexo vaginal SEM camisinha

c. Beijo na boca

d. Compartilhar o banheiro com um portador do virus

- Compartilhar seringas para o uso de drogas

Beber no mesmo copo que un portador do virus

Z Sexo anal COM camisinha

2) Hoje en dia, quem tem mais chances de contrair AIDS ? (Assinale somente uma altemativa)

a. Homossexuais (gays)

b. Travestis

c. Homens heterossexuais

d. Mulheres heterossexuai

e. Idosos

f. Qualquer pessoa tem a mesma chance de contrair AIDS se fizer seso sem camisinha

3) Sảo métodos indicados para evitar contrair DSTs: (Pode assinalar várias altemativas)

a. Pilula do dia seguinte

b. Camisinha masculin

c. Camisinha feminina

d. Coito interrompido (gozar fora)

e. Tabelinha

f. Pilula anticoncepcional

2 DUU - dispositivo intra-iterino

4) Assinale as afirmaçôes comretas: (Pode assinalar várias altemativas)

a. Homossexualidade é anormal.

b. Masturbação provoca espinhas

c. A camisinha e o unico método para evitar doenças transmitidas pelo sex.

d. So os homens se masturbam

e. Canisinha tira a sensibilidade

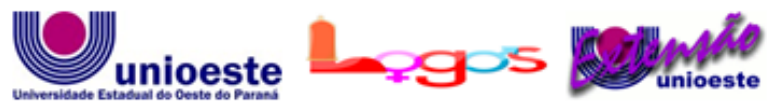

PROJETO LOGOS - Avaliação dos ahunos pós-oficinas

Colégio:

1) Assinale somente as maneiras em que se transmite 0 virus da AIDS: (Pode assinalar várias altemativas)

a. Sexo oral SEM camisinh

b. Sexo vaginal SEM camisinha

c. Beijo na boca

d. Compartilhar o banheiro com um portador do virus

e. Compartilhar seringas para o uso de drogas

f. Beber no mesmo copo que um portador do vírus

g. Sexo anal COM camisinha

2) Hoje em dia, quem tem mais chances de contrair AIDS (Assinale somente uma altemativa)

a. Homossexuais (gays)

b. Travestis

c. Homens heterossexuais

d. Nulheres heterossexuais

e. Idosos

f. Qualquer pessoa tem a mesma chance de contrair $A$ IDS se fizer sexo sem camisinha

3) Sâo metodos indicados para evitar contrair DSTs: (Pode ass inalar várias altemativas)

a. Pilula do dia seguinte

b. Camisinha masculina

c. Camisinha feminina

d. Coito interrompido (gozar fora)

e. Tabelinha

g DIU - dispositivo intra-uterino

4) Assinale as afirmaçōes corretas: (Pode assinalar várias altemativas)

a. Homossexualidade é anomal

b. Masturbação provoca espinhas

c. A camisinha é o único método para evitar doenças transmitidas pelo sexo

d. So os homens se masturbam

e. Camisinha tira a sensibilidade

5) O quanto vocé aprendeu com o projeto?

() Muito ( ) Mais ou menos

( ) Pouco ( ) Nada

Você acha que o projeto mudara as suas atitudes e de seus colegas relacionadas ao sexo?

)Mudara muito( ) Mudará pouco ( ) Mudara nada

Você acha que o projeto mudará as suas atitudes e de seus colegas relacionadas

a SEXUALIDADE?

( ) Mudara muito ( )Mudará pouco ( )Mudará nada 